\title{
Recyclable Pd ionic catalyst coated on cordierite monolith for high TOF Heck coupling reaction
}

\author{
SHRIKANTH K BHAT ${ }^{\mathrm{a}, \mathrm{b}}$, JAGADEESH D PRASAD ${ }^{\mathrm{b}, *}$ and M S HEGDE ${ }^{\mathrm{a}, *}$ \\ ${ }^{a}$ Talent Development Centre, Indian Institute of Science, Challakere Campus, Chitradurga, Karnataka 577 536, \\ India \\ ${ }^{\mathrm{b}}$ Department of Chemistry, Mangalagangotri, Mangalore University, Konaje, Mangalore 574 199, India \\ E-mail: jprasad2003@gmail.com; mshegde@iisc.ac.in
}

MS received 16 November 2018; revised 19 December 2018; accepted 2 January 2019; published online 13 February 2019

\begin{abstract}
Pd}^{2+}$ ionic catalyst, $\mathrm{Ti}_{0.97} \mathrm{Pd}_{0.03} \mathrm{O}_{1.97}$ was coated over cordierite monolith by solution combustion method. The catalyst coated on the cordierite is nano-crystalline as seen from XRD studies. Coated catalyst was used for Heck coupling reactions with different substrates of aryl halides and olefins. Thus handling nanocrystalline catalyst powder is avoided by fixing it on a solid catalyst cartridge. Heck coupled products were characterized using ${ }^{1} \mathrm{H}$ NMR, ${ }^{13} \mathrm{C}$ NMR, Mass and FTIR spectroscopy. This catalyst showed high selectivity towards Heck coupling reaction. Turnover frequencies (TOF) for each of the reactions were found to be very high. The catalyst was recycled up to 7 times with total TOF $3017 \mathrm{~h}^{-1}$, which is found to be a new green technique in the Heck coupling reaction.
\end{abstract}

Keywords. Noble metal ionic catalyst; cordierite monolith; solution combustion method; Heck coupling.

\section{Introduction}

The Heck coupling reaction has been considered as one of the most widely used a method for the formation of CC bonds. ${ }^{1-4}$ Literature indicated the application of this coupling reaction in the synthesis of complex organic molecules such as drugs, natural products and advanced materials. ${ }^{5-11}$ For these reactions, Pd based catalysts were used extensively where they ensure enhanced reaction rates, high turnover frequencies and very good selectivity. ${ }^{12-14}$ Homogeneous palladium-based catalysts are extensively used in Heck coupling reaction as it provides high reaction rates and turnover number (TON) and often ends up with high selectivity and yields. ${ }^{15-17}$ In these cases, Palladium catalyst can be activated with the help of ligands such as phosphines, carbines, amines and dibenzylidene acetone(dba). On the other hand, homogeneous catalysis has a number of drawbacks such as reusing of the catalyst and impurities in the products which leads to loss of expensive
Palladium metal, ligands and the need to remove a metal particle from the products. ${ }^{18}$ Due to the high cost of Palladium and environmental issues, the development of heterogeneous catalysis is important for the industrial application to perform such coupling reactions. Therefore researchers are looking towards a heterogeneous catalyst which is highly stable and reusable. ${ }^{19-23}$ Recent studies show that $\mathrm{PdO}$ supported carbon nanomaterials $^{24}$ and palladium( 0 ) on copper ferrite nanowires were designed for traditional Heck reaction as well as Heck reaction between iodoarenes and allylic alcohols. ${ }^{25}$

Instead of $\mathrm{Pd}$ metal nanoparticles or $\mathrm{PdO}, \mathrm{Pd}^{2+}$ ion substituted in reducible oxides showed high rates of redox catalytic reactions. A new class of catalysts called "Noble Metal Ionic Catalysts" (NMIC) were developed here. ${ }^{29}$ Noble metal ions substituted in reducible oxide such as $\mathrm{TiO}_{2}$ is a new class of catalyst which was synthesized by solution combustion method. ${ }^{26-29}$ Among different metals, Pd showed very good catalytic activity for $\mathrm{CO}$ oxidation reaction,

\footnotetext{
*For correspondence

Electronic supplementary material: The online version of this article (https://doi.org/10.1007/s12039-019-1594-9) contains supplementary material, which is available to authorized users.
} 
hydrocarbon oxidation reaction and hydrogen-oxygen recombination reaction. ${ }^{27-30}$ When catalyst coated over cordierite monolith, it showed very good catalytic activity towards hydrogen-oxygen recombination reaction at room temperature. ${ }^{31}$ On $\mathrm{Pd}^{2+}$ ion substitution in $\mathrm{TiO}_{2}$ lattice, a stable stoichiometric compound $\mathrm{Ti}_{1-x} \mathrm{Pd}_{x} \mathrm{O}_{2-x}$ $(\mathrm{x}=0.03)$ is formed with one oxide ion vacancy per $\mathrm{Pd}^{2+}$ ion for charge compensation. When $\mathrm{Pd}^{2+}$ is substituted, an oxide ion vacancy is automatically created in the lattice. $\mathrm{Pd}^{2+}$ ion and oxide ion vacancy were next to each other as seen from the structure. ${ }^{31} \mathrm{Pd}$ ion acted as an electrophile and oxide ion vacancy as a nucleophile. $\mathrm{TiO}_{2}$ is cheaper reducible oxide support and non-toxic. $100 \% \mathrm{Pd}$ ion dispersion is achieved so that all the $\mathrm{Pd}$ metal used becomes the active site.

Here we have attempted Heck coupling reaction with ionic palladium substituted $\mathrm{TiO}_{2}$ having composition $\mathrm{Ti}_{0.97} \mathrm{Pd}_{0.03} \mathrm{O}_{1.97}$. To avoid handling nano-material in the form of powder, and also to see if a catalyst cartridge can be developed, we coated the catalyst on cordierite monolith by solution combustion method. ${ }^{31,32}$ We have avoided the use of powder catalyst. The reaction was carried out with the solid monolith and removed it from the reaction flask, reused it and calculated overall TOF which was very high. The Heck coupling reaction was done in a specially designed reaction flask, which prevents breaking of cordierite monolith from fast rotating magnetic beads.

\section{Experimental}

\subsection{General}

$\mathrm{X}$-ray diffraction patterns of catalysts were recorded on a Philips X'Pert Diffractometer. Reactions were monitored by using pre-coated silica TLC plates. Mass spectra were recorded on EI and ESI (TOF) modes. NMR spectra were recorded in at $400 \mathrm{MHz}$ spectrometers in $\mathrm{CDCl}_{3}$, tetramethylsilane (TMS; $\delta=0.00 \mathrm{ppm}$ ) served as an internal standard for ${ }^{1} \mathrm{H}$ NMR. The corresponding residual non-deuterated solvent signal $\left(\mathrm{CDCl}_{3} ; \delta=77.00 \mathrm{ppm}\right)$ was used as internal standard for ${ }^{13} \mathrm{C}$ NMR. Column chromatography was carried out on silica gel 230-400 mesh or 100-200 mesh (SDFCL) and thin-layer chromatography was carried out using SILICA GEL GF-254. Chemicals obtained from Sigma Aldrich and SD Fine chemicals were used without further purification.

\subsection{Synthesis of $\mathrm{Ti}_{0.97} P d_{0.03} O_{1.97}$ powder catalyst}

The catalyst $\mathrm{Ti}_{0.97} \mathrm{Pd}_{0.03} \mathrm{O}_{1.97}$ was synthesized by solution combustion method. Titanium tetraisopropoxide $\left(\mathrm{Ti}\left(\mathrm{OC}_{3} \mathrm{H}_{7}\right)_{4}\right)$, palladium chloride and glycine were used as starting materials. A solution of $\mathrm{TiO}\left(\mathrm{NO}_{3}\right)_{2}(9.89 \mathrm{mmol})$, which was prepared from titanium tetraisopropoxide, $\mathrm{PdCl}_{2}$ $(0.31 \mathrm{mmol})$, and glycine $(10.99 \mathrm{mmol})$ were taken in a $300 \mathrm{~mL}$ crystallizing dish. The solution was kept in a $350^{\circ} \mathrm{C}$ preheated muffled furnace and combustion of starting materials took place followed by dehydration. The dish was kept inside the furnace for more than $20 \mathrm{~min}$ to burn all the carbon contents. Then the dish was removed from the furnace, allowed to cool and collected the catalyst powder. The catalyst was ground in a pestle and mortar and characterized by PXRD. The combustion reaction is given by:

$$
\begin{aligned}
& 9(1-\mathrm{x}) \mathrm{TiO}\left(\mathrm{NO}_{3}\right)_{2}+10(1-\mathrm{x}) \mathrm{C}_{2} \mathrm{H}_{5} \mathrm{NO}_{2} \\
& \quad+9 \mathrm{xPdCl}_{2} \rightarrow 9 \mathrm{Ti}_{1-x} \mathrm{Pd}_{x} \mathrm{O}_{2-\delta} \\
& \quad+20(1-\mathrm{x}) \mathrm{CO}_{2}+14(1-\mathrm{x}) \mathrm{N}_{2} \\
& \quad+(25-34 \mathrm{x}) \mathrm{H}_{2} \mathrm{O}+18 \mathrm{xHCl}: \mathrm{x}=0.01,0.02,0.03 .
\end{aligned}
$$

X-ray diffraction patterns were recorded on a Philips X'Pert Diffractometer at a scan rate of $0.1^{\circ} / \mathrm{min}$ with a step size in the $2 \theta$ range between $10^{\circ}$ and $90^{\circ}$. The diffraction profiles were refined by Rietveld refinement method.

\subsection{Coating of $\gamma-\mathrm{Al}_{2} \mathrm{O}_{3}$ over cordierite monolith}

Before coating the catalyst over monolith, $\gamma-\mathrm{Al}_{2} \mathrm{O}_{3}$ was coated over monolith to increase the surface area and adhesion to $\mathrm{TiO}_{2}$. This process was done by solution combustion method by taking $15 \mathrm{mmol}$ of $\mathrm{Al}\left(\mathrm{NO}_{3}\right)_{3}$ and $9 \mathrm{mmol}$ of glycine. A solution of starting materials was made and preweighed monolith was dipped in the solution and kept inside the furnace for combustion. After $15 \mathrm{~min}$, monolith was removed from the furnace and allowed to cool. The weight of the monolith was taken. This procedure was repeated until the weight of the coated $\gamma-\mathrm{Al}_{2} \mathrm{O}_{3}$ was 2 to $2.5 \%$ of cordierite monolith weight.

\subsection{Coating $T i_{0.97} P d_{0.03} O_{1.97}$ catalyst over cordierite monolith}

The solution was prepared in a beaker using starting materials such as $\mathrm{TiO}\left(\mathrm{NO}_{3}\right)_{2}$, palladium chloride and glycine. A piece of the pre-weighed monolith was dipped in the solution and kept inside the preheated muffled furnace for combustion. After 20-30 min the hot monolith was taken out and allowed to cool to room temperature. Then the cooled monolith was kept for sonication process to remove loosely held particles. The monolith was dried again to remove the moisture and allowed to cool down. This procedure was repeated to get the desired weight of catalyst to be coated. About $50 \mathrm{mg}$ of catalyst was coated on the monolith of $2.5 \mathrm{~cm}$ diameter, $2 \mathrm{~cm}$ height with 400 cells/inch. Alumina coated monolith and catalyst coated monolith are shown in Figure 1. We observed that catalyst becomes black during the reaction due to adsorption of olefins on palladium. After the reaction, catalyst is regenerated by heating at $200^{\circ} \mathrm{C}$ in the air for about $2 \mathrm{~h}$. Then it 


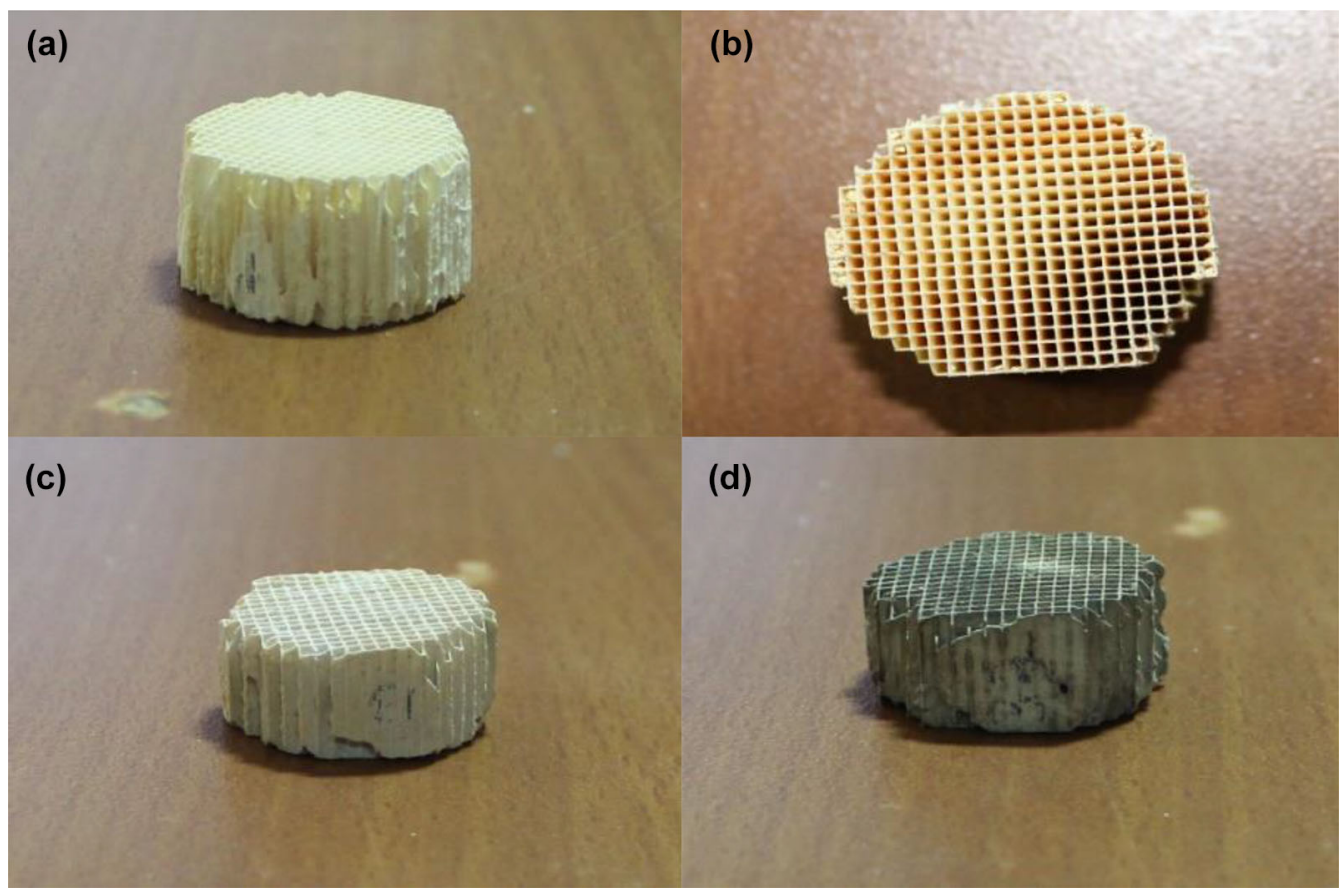

Figure 1. Photographs of (a) Alumina coated honeycomb monolith, (b) and (c) top view and side view of catalyst coated monolith respectively, (d) catalyst coated honeycomb after several cycles of reactions.

can be reused for many cycles consecutively. This Pd catalyst showed excellent catalytic activity towards Heck coupling reaction.

\subsection{Procedure for the Heck coupling reaction}

Screening reactions were carried out in $25 \mathrm{~mL}$ round bottom flask. Iodobenzene ( $200 \mathrm{mg}, 1$ equivalent), methyl acrylate (1.1 equivalents), catalyst $\left(10 \mathrm{mg}\right.$ ) and $\mathrm{K}_{2} \mathrm{CO}_{3}$ (1.5 equivalent) were taken into a $25 \mathrm{~mL}$ round bottom flask. $3 \mathrm{~mL}$ of DMF was added. The reaction was kept under an argon atmosphere at $110^{\circ} \mathrm{C}$. Reaction was monitored by TLC. Extracted the product with diethyl ether and 3 times water work up. Percentage of yield was determined by using gas chromatography.

Heck coupling reactions were done in the specially designed reaction flask. Aryl halides ( $2 \mathrm{~g}, 1$ equivalent), olefins ( 1.1 equivalents) and base (1.5 equivalents) were taken into the reaction flask. Catalyst coated cordierite monolith was put inside the flask. The reaction was kept under an argon atmosphere at $110^{\circ} \mathrm{C}$. The reaction was monitored by TLC. After completion of the reaction, the coupled product was extracted by diethyl ether and washed 3 times with water to remove the solvents and base. Catalyst coated monolith was removed from the flask, washed with water to remove solvent and base. Then washed with $\mathrm{n}$-hexane to remove organic impurities and dried in a hot air oven for $2 \mathrm{~h}$ at $200^{\circ} \mathrm{C}$. Dried catalyst cartridge was reused for two more substrates of Heck coupling reactions.
The product was isolated using column chromatography. The eluents used were pet ether and ethyl acetate. The ratio was standardised by using TLC according to the polarity of the products. Coupled products were characterized by ${ }^{1} \mathrm{H}$ NMR, ${ }^{13} \mathrm{C}$ NMR, IR spectra and mass spectra.

\section{Results and Discussion}

Catalyst $\mathrm{Ti}_{0.97} \mathrm{Pd}_{0.03} \mathrm{O}_{1.97}$ was prepared by solution combustion method from the starting materials $\mathrm{TiO}\left(\mathrm{NO}_{3}\right)_{2}$, palladium chloride and glycine at $350{ }^{\circ} \mathrm{C}$. Pd substituted $\mathrm{TiO}_{2}$ crystalizes in anatase structure. Rietveld refined XRD pattern for 3 atoms $\% \mathrm{Pd}$ in $\mathrm{TiO}_{2}$ is given in Figure 2. There are no peaks either of $\mathrm{PdO}$ or $\mathrm{Pd}$ metal in the difference profile. Lattice parameters are: $\mathrm{a}=3.796$ $\AA$ and $c=9.534 \AA$ which are close to pure $\mathrm{TiO}_{2}$ values, $\mathrm{a}=3.796 \AA$ and $\mathrm{c}=9.533 \AA$. This is to be expected because the ionic radius of $\mathrm{Pd}^{2+}$ is $0.64 \AA$ which is close to that of $\mathrm{Ti}^{4+}(0.605 \AA)$. A detailed study of the structure of $\mathrm{Ti}_{0.97} \mathrm{Pd}_{0.03} \mathrm{O}_{1.97}$ has been reported earlier. ${ }^{31}$ The XRD patterns of cordierite monolith and catalyst coated cordierite monolith is shown in Figure 3. Cordierite monoliths are in cylindrical shape with $2.5 \mathrm{~cm}$ diameter and $2 \mathrm{~cm}$ height and are made up of $\mathrm{Mg}_{2} \mathrm{Al}_{4} \mathrm{Si}_{5} \mathrm{O}_{18}$. One can see the (101) diffraction line of the catalyst in the XRD pattern at angle $25.3^{\circ}$ in the difference plot between coated and uncoated cordierite monolith 


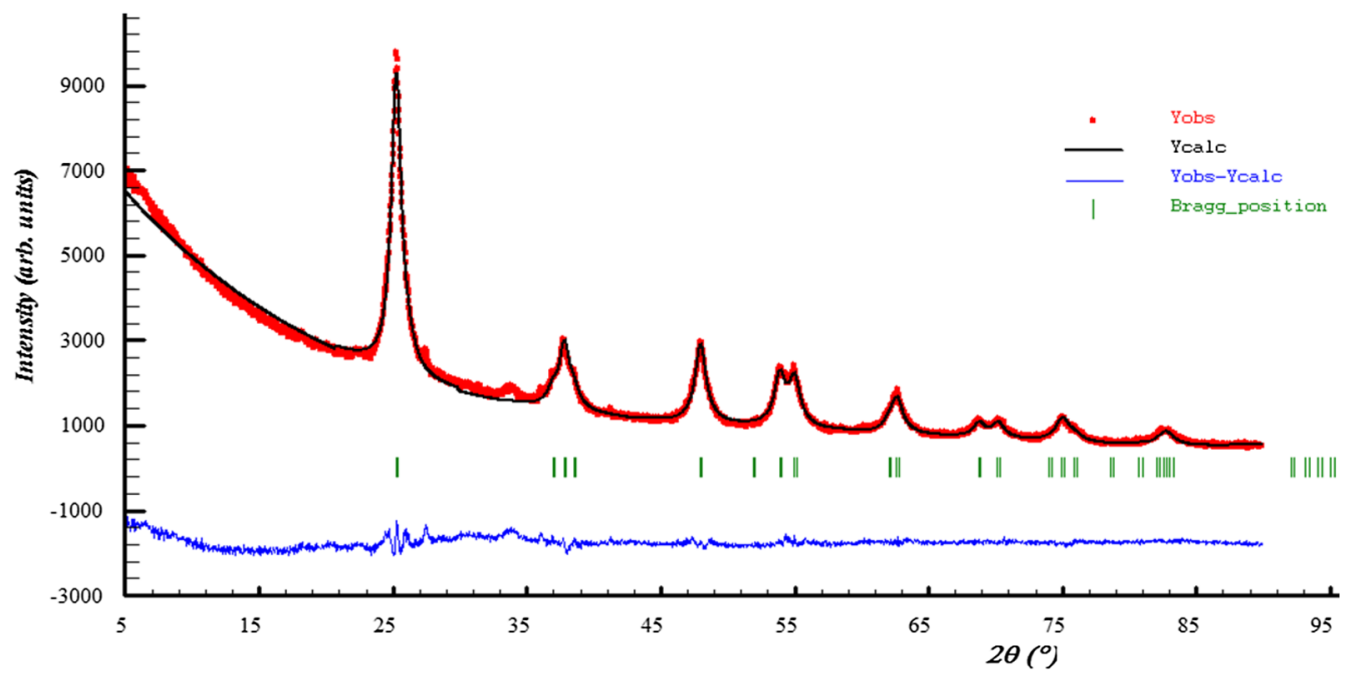

Figure 2. Rietveld refined XRD pattern of $\mathrm{Ti}_{0.97} \mathrm{Pd}_{0.03} \mathrm{O}_{1.97}$ catalyst. There is no peak of $\mathrm{Pd}$ metal or $\mathrm{TiO}_{-2}$ rutile phase, which confirms the formation of single phase Pd substituted catalyst.

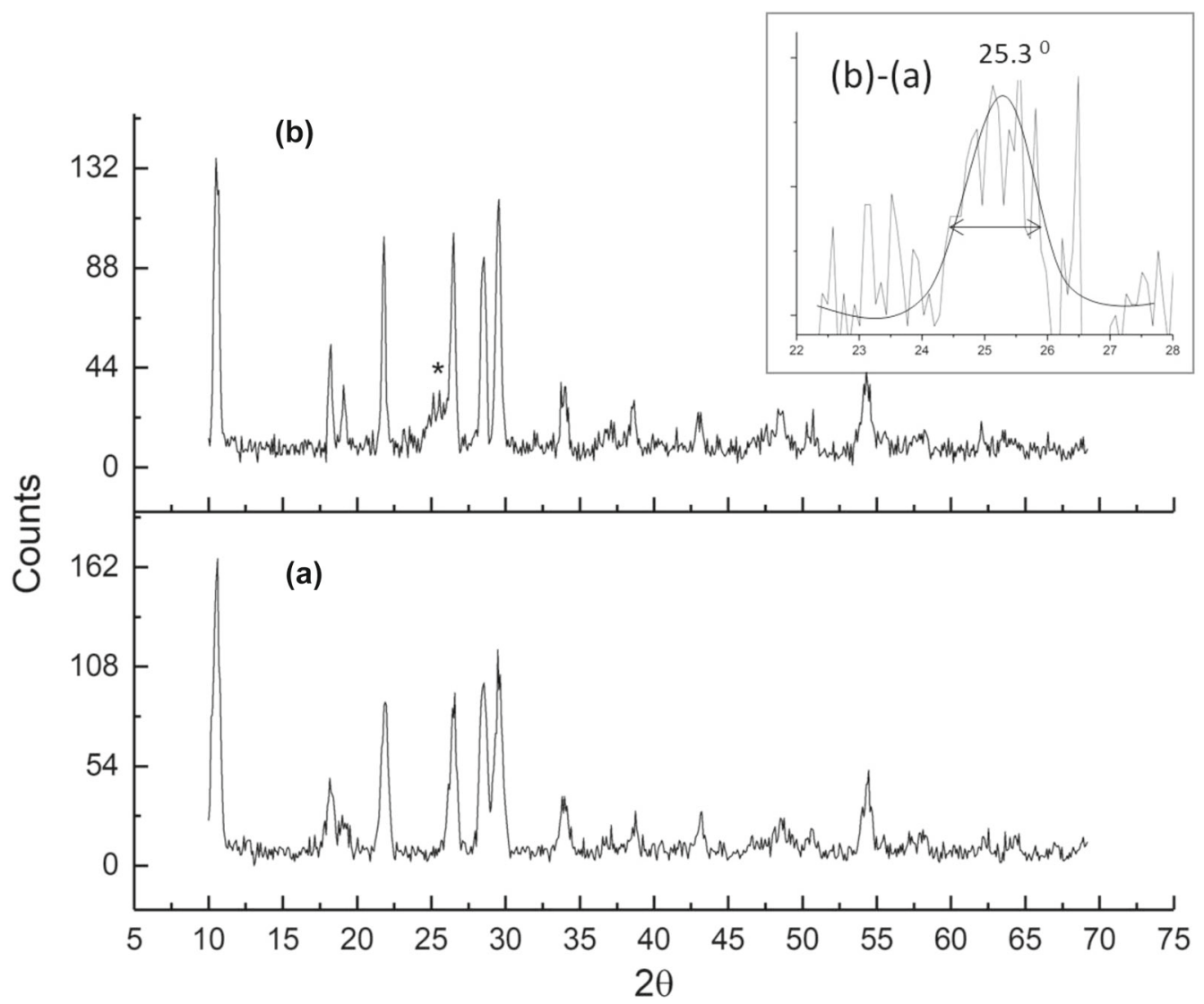

Figure 3. Powder XRD patterns of (a) cordierite monolith, (b) catalyst coated over cordierite monolith and inset figure showing a broad peak of (101) line of the catalyst. * (101) line of $\mathrm{Ti}_{0.97} \mathrm{Pd}_{0.03} \mathrm{O}_{1.97}$.

shown inset of Figure 3. Each monolith is having parallel channels of a square shape. Thus high surface area is exposed to the reactants. The color of the catalyst is brown. Average crystallite size is $8 \pm 2 \mathrm{~nm}$ which was calculated from half-width of (101) line of coated catalyst (inset of Figure 3) using Scherrer formula $(d=0.9$ 
$\lambda / \beta \cos \theta)$ in the powder and on the surface also a similar size is expected because half width of the (101) peak is of the same order.

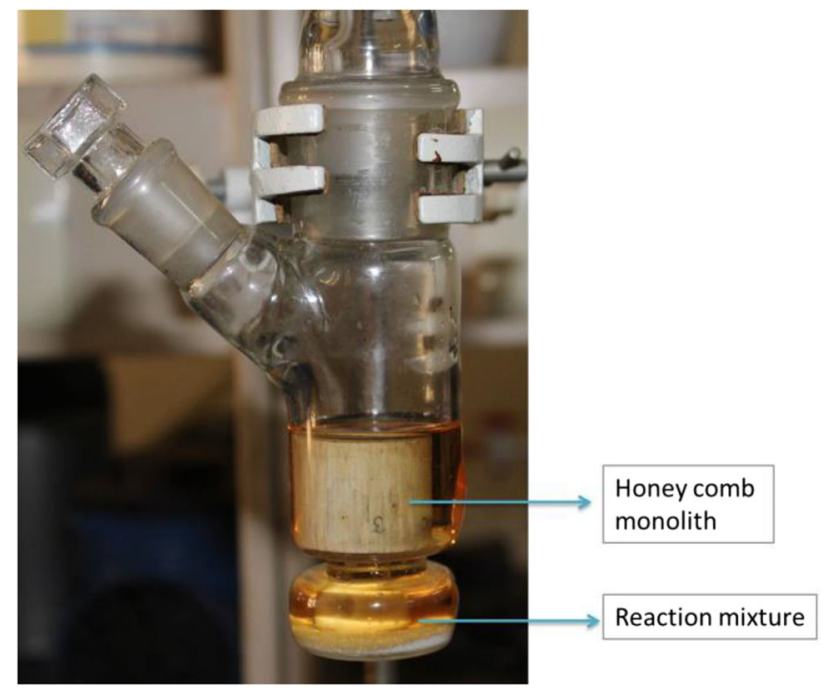

Figure 4. Specially designed reaction flask for Heck coupling reaction with the reaction mixture and coated honeycomb catalyst.

\subsection{Heck coupling reaction flask}

Figure 4 shows the two-necked cylindrical flask with diameter $3.5 \mathrm{~cm}$ and height $12 \mathrm{~cm}$. Above $1.5 \mathrm{~cm}$ from the bottom, the diameter of the flask is reduced to make two separate compartments with a small passage between them. The bottom space contained magnetic bead and reaction mixture. Above the passage, the catalyst coated honeycomb (HC) catalyst was placed. The sufficient solvent was taken such that the HC catalyst was submerged in the solvent. Condenser and argonfilled balloon were fitted above the flask. The flask was kept on preheated oil bath at temperature $110^{\circ} \mathrm{C}$. The rotation speed of stirrer was high enough to circulate reaction mixture with solvent through the $\mathrm{HC}$ catalyst.

\subsection{Screening studies}

Screening of the Heck coupling reaction was started with the reaction of iodobenzene and methyl acrylate as starting materials. Powder catalyst was used in each of the screening reaction. $0.98 \mathrm{mmol}(200 \mathrm{mg})$ of Iodobenzene and 1.1 equivalent of methyl acrylate were taken.

Table 1. Screening of the reaction.

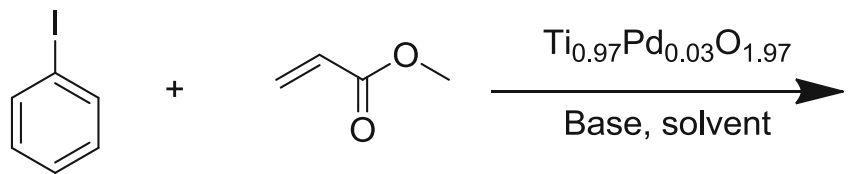<smiles>COC(=O)/C=C/c1ccccc1</smiles>

\begin{tabular}{|c|c|c|c|c|c|}
\hline Entry & Base & Solvent & Time (h) & Temp. $\left({ }^{\circ} \mathrm{C}\right)$ & Yield (\%) \\
\hline 1. & $\mathrm{~K}_{2} \mathrm{CO}_{3}$ & Acetonitrile & 4 & 110 & Nil \\
\hline 2. & $\mathrm{~K}_{2} \mathrm{CO}_{3}$ & DMSO & 4 & 110 & 20 \\
\hline 3. & $\mathrm{~K}_{2} \mathrm{CO}_{3}$ & DMF & 1.5 & 110 & $>99\left(95^{b}\right)$ \\
\hline 4. & $\mathrm{~K}_{2} \mathrm{CO}_{3}$ & 1,4-Dioxane & 4 & 110 & Nil \\
\hline 5. & $\mathrm{~K}_{2} \mathrm{CO}_{3}$ & THF & 4 & 110 & Trace \\
\hline 6. & $\mathrm{~K}_{2} \mathrm{CO}_{3}$ & NMP & 4 & 110 & 35 \\
\hline 7. & $\mathrm{~K}_{2} \mathrm{CO}_{3}$ & Toluene & 4 & 110 & Nil \\
\hline 8. & - & DMF & 2 & 110 & Trace \\
\hline 9. & $\mathrm{Cs}_{2} \mathrm{CO}_{3}$ & DMF & 2 & 110 & 34 \\
\hline 10. & $\mathrm{NEt}_{3}$ & DMF & 2 & 110 & 97 \\
\hline 11. & $\mathrm{CH}_{3} \mathrm{COONa}$ & DMF & 2 & 110 & 30 \\
\hline 12. & $\mathrm{t}-\mathrm{BuONa}$ & DMF & 2 & 110 & Nil \\
\hline 13. & $\mathrm{KOH}$ & DMF & 2 & 110 & 93 \\
\hline 14. & $\mathrm{~K}_{2} \mathrm{CO}_{3}$ & DMF & 2 & 80 & 16 \\
\hline 15. & $\mathrm{~K}_{2} \mathrm{CO}_{3}$ & DMF & 2 & 60 & Trace \\
\hline 16. & $\mathrm{~K}_{2} \mathrm{CO}_{3}$ & DMF & 8 & RT & Trace \\
\hline 17. & $\mathrm{~K}_{2} \mathrm{CO}_{3}$ & DMF & 1 & 110 & $>99^{c}\left(92^{b}\right)$ \\
\hline 18. & $\mathrm{~K}_{2} \mathrm{CO}_{3}$ & DMF & 1 & 110 & $>99^{\mathrm{d}}\left(94^{\mathrm{b}}\right)$ \\
\hline 19. & $\mathrm{~K}_{2} \mathrm{CO}_{3}$ & DMF & 2 & 110 & $93^{\mathrm{e}}$ \\
\hline 20. & $\mathrm{~K}_{2} \mathrm{CO}_{3}$ & $\mathrm{DMF}$ & 2 & 110 & $92^{f}$ \\
\hline
\end{tabular}

Reaction conditions: 1 equivalent $(200 \mathrm{mg}$ ) of Iodobenzene, 1.1 equivalent of Methyl acrylate, 1.5 equivalent of base, $3 \mathrm{~mL}$ of solvent, 5 weight $\%$ of powder catalyst, temperature at $110^{\circ} \mathrm{C}$, under Ar atmosphere. All are GC yield. b Isolated yield, ${ }^{\mathrm{c}} 50 \mathrm{mg}$ of catalyst coated over monolith, ${ }^{\mathrm{d}} 100 \mathrm{mg}$ of catalyst coated over catalyst, ${ }^{\mathrm{e}} 0.5$ equivalent of base, ${ }^{\mathrm{f}} 1 \mathrm{equivalent}$ of base. The converted reactions that are complete are given in bold. 
Table 2. Substrate scope of the reaction.

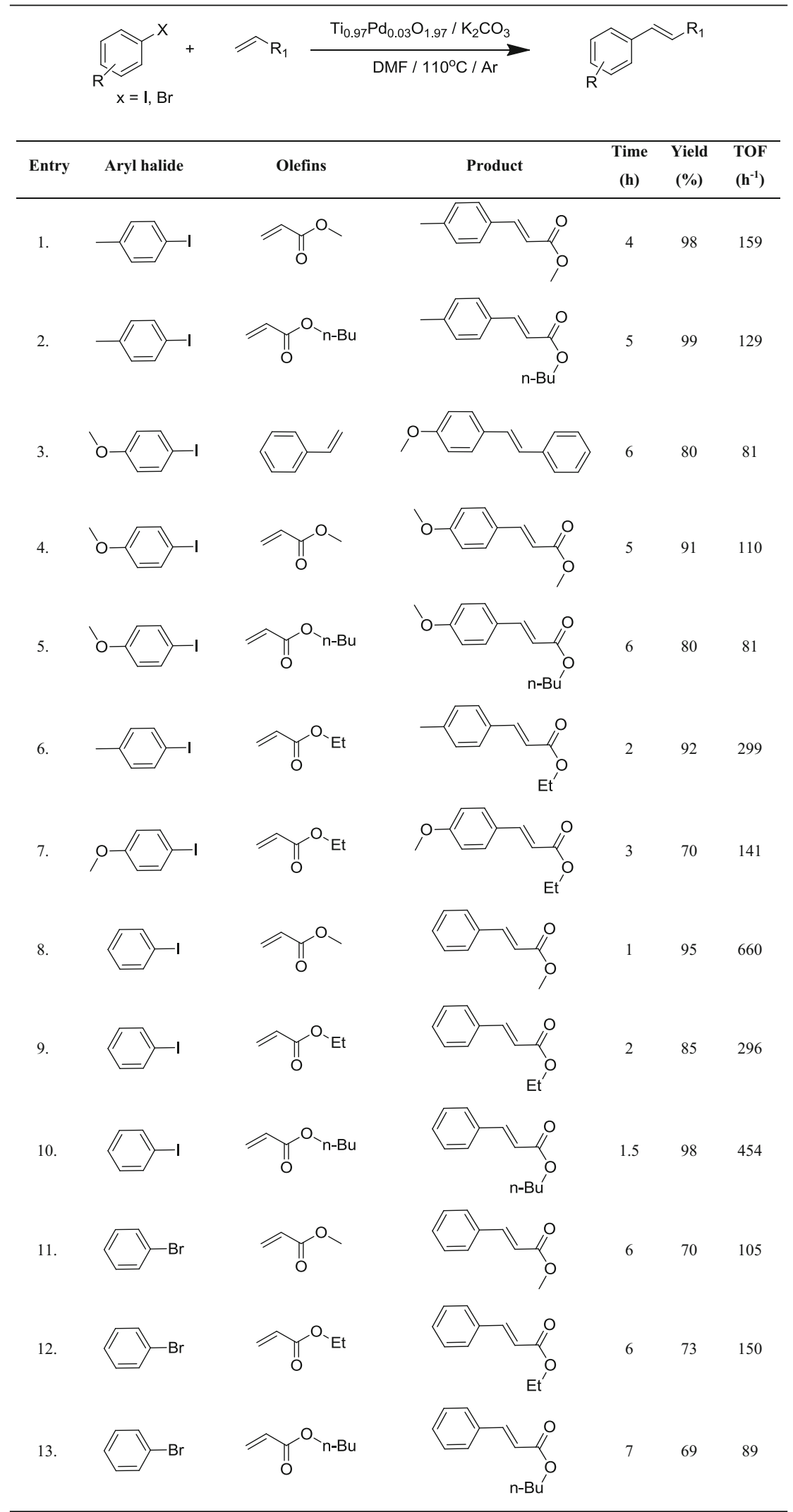


Table 2. (contd.)

20.

Reaction condition: 1 equivalent $(2 \mathrm{~g})$ of aryl halide, 1.1 equivalent of olefins, 1.5 equivalent of $\mathrm{K}_{2} \mathrm{CO}_{3}$ as base, $20 \mathrm{~mL}$ of DMF as solvent, $50 \mathrm{mg}$ catalyst coated over honeycomb monolith, temperature at $110^{\circ} \mathrm{C}$, under $\mathrm{Ar}$ atmosphere. All are isolated yield.

$\mathrm{TOF}=[($ No. of moles of product/ No. of moles of active site of catalyst $)] /$ time in hours.

$10 \mathrm{mg}$ of catalyst was used which contains $3.7 \mu \mathrm{mol}$ of $\mathrm{Pd}^{2+}$ ion. Initially, solvent study was carried where different solvents were used for the reaction. Except for the reaction in $N, N$-dimethyl formamide (DMF) as a solvent, all other reactions with different solvents have given almost negligible yield. Time of the reaction with solvent DMF was $90 \mathrm{~min}$ at temperature $110^{\circ} \mathrm{C}$ using $\mathrm{K}_{2} \mathrm{CO}_{3}$ (1.5 equivalent) as a base. We tried the reaction without base and resulted with a trace amount of yield. Then we investigated the reaction with 1.5 equivalent of different bases such as $\mathrm{Cs}_{2} \mathrm{CO}_{3}, \mathrm{NEt}_{3}, \mathrm{CH}_{3} \mathrm{COONa}$, t$\mathrm{BuONa}$ and $\mathrm{KOH}$, the reaction with $\mathrm{NEt}_{3}$ and $\mathrm{KOH}$ have ended up with very good yield same as that of $\mathrm{K}_{2} \mathrm{CO}_{3}$. Next step of screening was temperature; reactions were done at $80^{\circ} \mathrm{C}, 60^{\circ} \mathrm{C}$ and at room temperature, the yields were very low. So we have decided to keep DMF as a solvent, 1.5 equivalent of $\mathrm{K}_{2} \mathrm{CO}_{3}$ as base and temperature at $110^{\circ} \mathrm{C}$ as standard reaction condition for the Heck coupling reaction. We have also tried the reaction with 1 and 0.5 equivalent of $\mathrm{K}_{2} \mathrm{CO}_{3}$ and observed slightly lesser yield compared to 1.5 equivalent of base. We have done two more reactions using honeycomb monolith catalyst where, one monolith was coated with $100 \mathrm{mg}$ catalyst, another with $50 \mathrm{mg}$ of catalyst. $2 \mathrm{~g}$ of iodobenene was used as starting material. Both the reactions were ended up with yield more than $99 \%$. Interestingly, the time taken for these two reactions was just one hour. Compared to the reactions with powder catalyst, honeycomb 


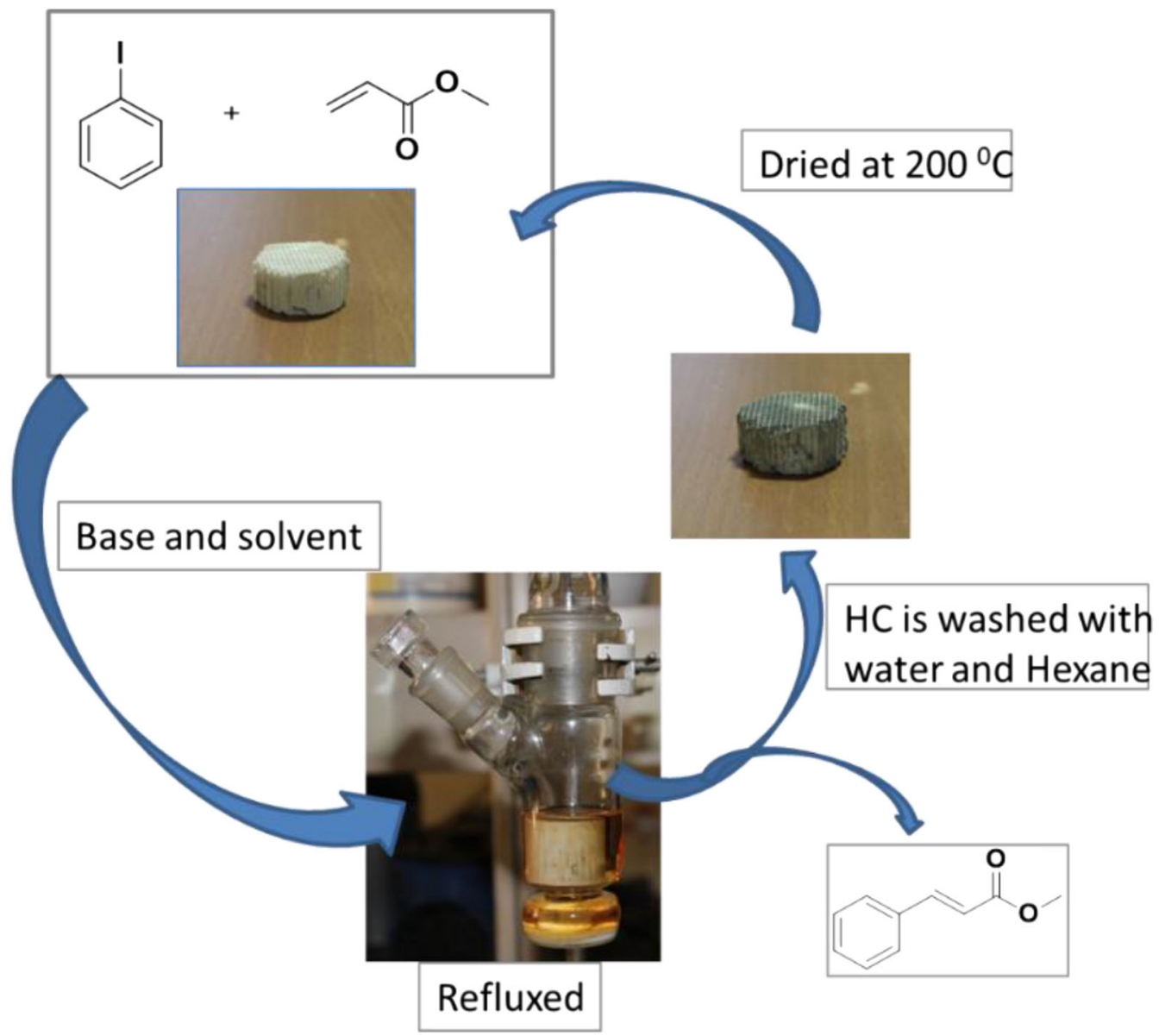

Figure 5. Flowchart of recycling of $\mathrm{HC}$ monolith catalyst in the Heck coupling reaction.

monolith catalyst shown faster rate. Finally, we decided to coat $50 \mathrm{mg}$ of catalyst over cordierite monolith for the remaining reactions. The screening of Heck coupling reactions is summarised in Table 1.

\subsection{Substrate scopes}

22 substrates of aryl halides and olefins were used for substrate scope of the Heck coupling reaction listed in Table 2. We have used optimized condition that is 1 equivalent of aryl halide ( $2 \mathrm{~g}), 1.1$ equivalent of olefins, 1.5 equivalent of $\mathrm{K}_{2} \mathrm{CO}_{3}$ as a base and $20 \mathrm{~mL}$ of DMF as a solvent. About $50 \mathrm{mg}$ of catalyst was coated on cordierite monolith and every reaction was done with the coated catalyst. Substituted aryl iodide compounds showed very good reactivity towards olefins despite having electron-withdrawing and electron-donating groups (Table 2, entry 1-7); the time taken for the reaction was about $5 \mathrm{~h}$. The reaction between un-substituted iodobenzene showed very high reactivity (Table 2, entry 8-10, 16-18) towards different olefins with very high TOF. The TOF of the reaction between iodobenzene and methyl acrylate was found to be $660 \mathrm{~h}^{-1}$ which is highest among all other substrates. Substrate scope of aryl bromides were also done, yields were above $50 \%$ in case of aryl bromides, but the time taken for the reactions were about 6 to $8 \mathrm{~h}$. Because of less reactivity of bromides, the TOF were low compared to iodo substrates (Table 2, entry 11-15). Finally 1 - chloro 4 - iodobenzene reacted with different olefins (Table 2, entry 20-22), reaction were ended up with more than $75 \%$ yield by substitution at iodo position and chlorides remained as it is in the product which is confirmed by mass spectra. All products were isolated and found to be trans from ${ }^{1} \mathrm{H}$ NMR. The catalyst was well-tolerated to different varieties of aryl halides and olefins. Reaction with aryl iodide ended up with very good yield compared to aryl bromide.

\subsection{Recycling of the catalyst}

We have carried out the recycling of the catalyst for several cycles. Iodobenzene ( $2 \mathrm{~g})$ and methyl acrylate (1.1 equiv.) were taken as starting materials by employing standard conditions. The whole process of recycling the $\mathrm{HC}$ monolith catalyst is depicted in Figure 5. After each 


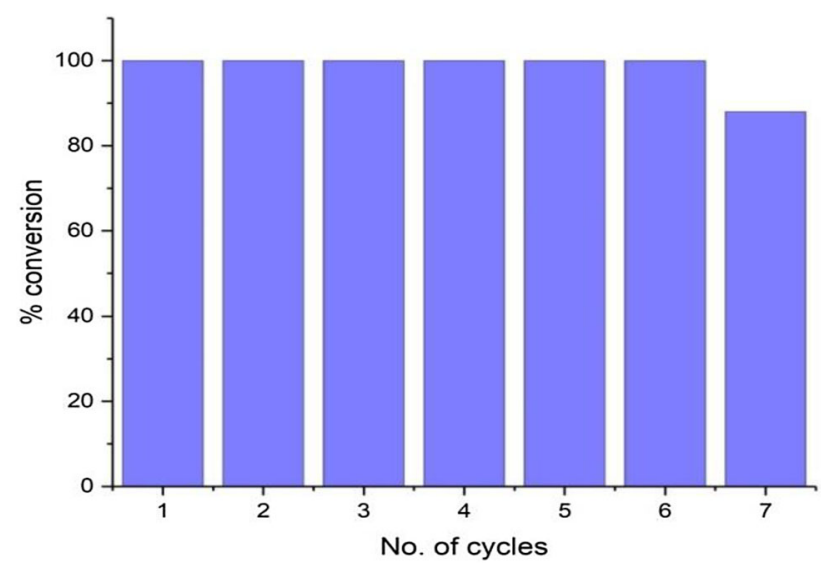

Figure 6. Recycling of the catalyst by employing standard reaction condition.

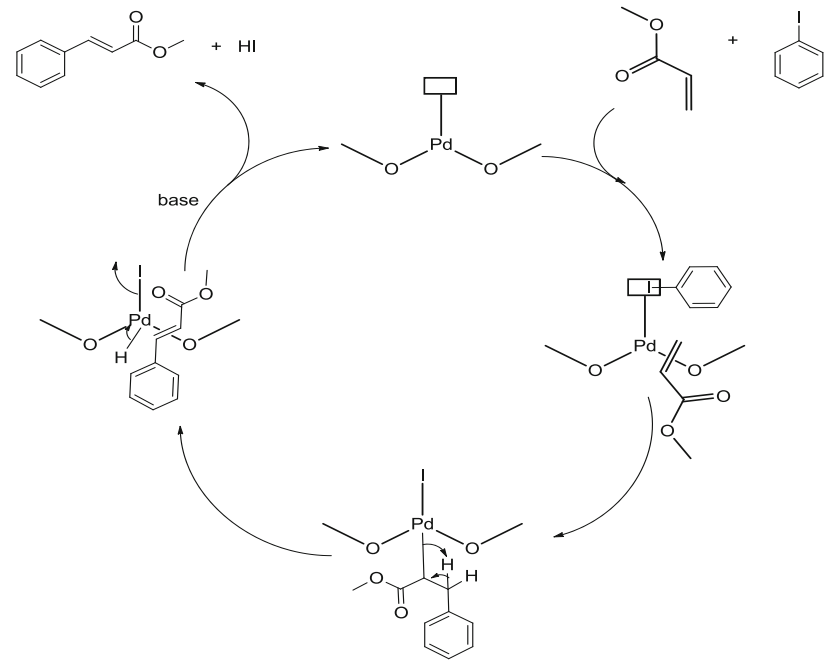

Figure 7. The mechanism for Heck coupling reaction with $\mathrm{Ti}_{0.97} \mathrm{Pd}_{0.03} \mathrm{O}_{1.97}$ catalyst.

cycle, the used monolith was taken out from the reaction flask and washed with distilled water to remove base and solvent, then washed with hexane to remove organic impurities. Washed monolith was dried in a hot air oven at a temperature $200{ }^{\circ} \mathrm{C}$ for $2 \mathrm{~h}$. Dried monolith was reused for another reaction. We obtained $100 \%$ yield up to 6th cycle and in the 7th cycle, we observed a drop in the yield to $85 \%$. The recycling chart of the catalyst is given in Figure 6. The reaction time up to 6th cycle was 1 to $3 \mathrm{~h}$ and in 7 th cycle, reaction time was $14 \mathrm{~h}$. Total TOF after 7 cycles of the reaction was $3017 \mathrm{~h}^{-1}$.

\subsection{Mechanism for the Heck coupling reaction}

A mechanism is proposed for the Heck coupling reaction with $\mathrm{Ti}_{0.97} \mathrm{Pd}_{0.03} \mathrm{O}_{1.97}$ catalyst is given in Figure 7 . The catalyst is $\mathrm{Ti}_{0.97} \mathrm{Pd}_{0.03} \mathrm{O}_{1.97}$ where for every $\mathrm{Pd}^{2+}$ ion there is an oxide ion vacancy. Pd ion is electron deficient and the oxide ion vacancy is electro rich. The active site in the catalyst is $\mathrm{Pd}^{2+}$ ion. There was no Heck reaction on pure $\mathrm{TiO}_{2}$ which means that neither $\mathrm{Ti}^{4+}$ nor $\mathrm{O}^{2-}$ is the active sites in the catalyst. Olefins bind with $\mathrm{Pd}^{2+}$ ions because olefins can donate $\pi$ electrons and thus becomes a normal site for the adsorption of olefin. -I or $-\mathrm{Br}$ of aryl halides that are accommodated on oxide ion vacancy of the catalyst. Here oxide ion vacancy acts as a nucleophile. HI is eliminated with the help of base, which leads to $\mathrm{C}-\mathrm{C}$ coupling.

\section{Conclusions}

In summary, we have developed a new class of catalyst for the $\mathrm{C}-\mathrm{C}$ coupling reaction. This method is environmentally friendly without using any toxic catalyst or reagents. This reaction tolerates a variety of functional groups. Reactions were done using catalyst coated over cordierite monolith by a unique method, which is also helpful for recovering the catalyst.

\section{Supplementary Information (SI)}

Supplementary information is available at www.ias.ac.in/ chemsci.

\section{References}

1. Beletskaya I P and Cheprakov A V 2000 The Heck Reaction as a Sharpening Stone of Palladium Catalysis Chem. Rev. 1003009

2. Reetz M T, Lohmer G and Schiwikardi R 1998 A new catalyst for the Heck reaction of unreactive aryl halides Angew. Chem. Int. Ed. 137481

3. Heck R F 1968 Arylation, Methylation, and Carboxy alkylation of Olefins by Group VIII Metal Derivatives $J$. Am. Chem. Soc. 905518

4. Yin L and Liebscher J 2007 Carbon-Carbon coupling reactions catalysed by heterogeneous palladium catalysts Chem. Rev. 107133

5. Lin B, Huang S, Wu W, Mou C and Tsai F 2010 Sonogashira reaction of aryl and heteroaryl halides with terminal alkynes catalyzed by a highly efficient and recyclable nanosized MCM-41 anchored palladium bipyridyl complex Molecules 159157

6. Biajoli A F P, Schwalm C S, Limberger J, Claudino T S and Monteiro A L 2014 Recent progress in the use of Pdcatalyzed $\mathrm{C}-\mathrm{C}$ cross-coupling reactions in the synthesis of pharmaceutical compounds J. Braz. Chem. Soc. 25 2186

7. Magano J and Dunetz J R 2011 Large-Scale Applications of Transition Metal-Catalysed Couplings for the Synthesis of Pharmaceuticals Chem. Rev. 1112177

8. Roughley S D and Jordan A M 2011 The medicinal chemist's toolbox: An analysis of Reactions used in the pursuit of drug candidates J. Med. Chem. 543451 
9. Nicolaou K C, Bulger P G and Sarlah D 2005 PalladiumCatalysed Cross-Coupling Reactions in Total Synthesis Angew. Chem. Int. Ed. 444442

10. Denmark S E and Hurd A R 2000 Synthesis of (+)Casuarine J. Org. Chem. 652875

11. Häberli A and Leumann C J 2001 Synthesis of Pyrrolidine $C$-Nucleosides via Heck Reaction Org. Lett. 3489

12. de Vries A H M, Mulders J M C A, Mommers J H M, Henderickx H J W and de Vries J G 2003 Homeopathic Ligand-Free Palladium as a Catalyst in the Heck Reaction. A Comparison with a Palladacycle Org. Lett. 5 3285

13. Crisp G T 1998 Variations on a theme-recent developments on the mechanism of the Heck reaction and their implications for synthesis Chem. Soc. Rev. 27427

14. Dieck H A and Heck R F 1974 Organophosphinepalladium Complexes as Catalysts for Vinylic Hydrogen Substitution Reactions J. Am. Chem. Soc. 96 1133

15. (a) Littke A F and Fu G C 1999 Heck Reactions in the Presence of $\mathrm{P}(\mathrm{t}-\mathrm{Bu})_{3}$ : Expanded Scope and Milder Reaction Conditions for the Coupling of Aryl Chlorides J. Org. Chem. 64 10; (b) Littke A F and Fu G C 2001 A Versatile Catalyst for Heck Reactions of Aryl Chlorides and Aryl Bromides under Mild Conditions J. Am. Chem. Soc. 1236989

16. Yang C, Lee H M and Nolan S P 2001 Highly Efficient Heck Reactions of Aryl Bromides with n-Butyl Acrylate Mediated by a Palladium/Phosphine-Imidazolium Salt System Org. Lett. 31511

17. Xu L, Chen W and Xiao J 2000 Heck Reaction in Ionic Liquids and the in Situ Identification of N-Heterocyclic Carbene Complexes of Palladium Organometallics 19 1123

18. Garrett C E and Prasad K 2004 The Art of Meeting Palladium Specifications in Active Pharmaceutical Ingredients Produced by Pd-Catalyzed Reactions $A d v$. Synth. Catal. 346889

19. Sobhani $S$ and Pakdin-Parizi Z 2014 Palladium-DABCO complex supported on $-\mathrm{Fe}_{2} \mathrm{O}_{3}$ magnetic nanoparticles: A new catalyst for $\mathrm{C}-\mathrm{C}$ bond formation via MizorokiHeck cross-coupling reaction Appl. Catal. A: Gen. 479 112

20. Rostamnia S and Kholdi S 2017 Synthesis of hybrid interfacial silica-based nanospheres composite as a support for ultra-small palladium nanoparticle and application of $\mathrm{Pd}_{\mathrm{NPs}} / \mathrm{HSN}$ in Mizoroki-Heck reaction J. Phys. Chem. Solids 11147
21. Liu W, Wang D, Duan Y, Zhang Y and Bian F 2015 Palladium supported on poly (ionic liquid) entrapped magnetic nanoparticles as a highly efficient and reusable catalyst for the solvent-free Heck reaction Tetrahedron Lett. 561784

22. Sanjaykumar S R, Mukri B D, Patil S, Madras G and Hegde M S Ce $0.98 \mathrm{Pd}_{0.02} \mathrm{O}_{2-\delta}$ : Recyclable, ligand free palladium(II) catalyst for Heck reaction $2011 \mathrm{~J}$. Chem. Sci. 12347

23. Mpungose P P, Vundla Z P, Maguire G E M and Friedrich H B 2018 The Current Status of Heterogeneous Palladium Catalysed Heck and Suzuki Cross-Coupling Reactions Molecules 231676

24. Lakshminarayana B, Mahendar L, Ghosal P, Sreedhar B, Satyanarayana G and Subrahmanyam C 2018 Fabrication of $\mathrm{Pd} / \mathrm{CuFe}_{2} \mathrm{O}_{4}$ hybrid nanowires: a heterogeneous catalyst for Heck couplings New J. Chem. 421646

25. Lakshminarayana B, Mahendar L, Ghosal P, Satyanarayana G and Subrahmanyam C 2017 Nano-sized Recyclable PdO Supported Carbon Nanostructures for Heck Reaction: Influence of Carbon Materials ChemistrySelect 22700

26. Nagaveni K, Hegde M S and Madras G 2004 Structure and Photocatalytic Activity of $\mathrm{Ti}_{1-x} \mathrm{M}_{\mathrm{x}} \mathrm{O}_{2-\delta}(\mathrm{M}=\mathrm{W}, \mathrm{V}$, $\mathrm{Ce}, \mathrm{Zr}, \mathrm{Fe}$, and $\mathrm{Cu}$ ) Synthesized by Solution Combustion Method J. Phys. Chem. B 10820204

27. Hegde M S, Nagaveni K and Roy S 2005 Synthesis, structure and photocatalytic activity of nano $\mathrm{TiO}_{2}$ and nano $\mathrm{Ti}_{1-\mathrm{x}} \mathrm{M}_{\mathrm{x}} \mathrm{O}_{2-\delta}(\mathrm{M}=\mathrm{Cu}, \mathrm{Fe}, \mathrm{Pt}, \mathrm{Pd}, \mathrm{V}, \mathrm{W}, \mathrm{Ce}, \mathrm{Zr})$ Pramana - J. Phys. 65641

28. Mukri B D, Dutta G, Waghmare U V and Hegde M S 2012 Activation of Lattice Oxygen of $\mathrm{TiO}_{2}$ by $\mathrm{Pd}^{2+}$ Ion: Correlation of Low-Temperature $\mathrm{CO}$ and Hydrocarbon Oxidation with Structure of $\mathrm{Ti}_{1-\mathrm{x}} \mathrm{Pd}_{\mathrm{x}} \mathrm{O}_{2-\mathrm{x}}(\mathrm{x}=0.01$ 0.03) Chem. Mater. 244491

29. Hegde M S, Madras G and Patil K C 2009 Noble Metal Ionic Catalysts Acc. Chem. Res. 42704

30. Sharma $\mathrm{S}$ and Hegde M S $2009 \mathrm{Ti}_{0.99} \mathrm{Pd}_{0.01} \mathrm{O}_{2-\delta}$ : A New Pt-free Catalyst for High Rates of $\mathrm{H}_{2}+\mathrm{O}_{2}$ Recombination with High CO Tolerant Capacity ChemPhysChem $\mathbf{1 0}$ 637

31. Mukri B D and Hegde M S 2017 High rates of catalytic hydrogen combustion with air over $\mathrm{Ti}_{0.97} \mathrm{Pd}_{0.03} \mathrm{O}_{2-\delta}$ coated cordierite monolith J. Chem. Sci. 1291363

32. Sharma S and Hegde M S 2006 Single step direct coating of 3-way catalysts on cordierite monolith by solution combustion method: High catalytic activity of $\mathrm{Ce}_{0.98} \mathrm{Pd}_{0.02} \mathrm{O}_{2-\delta}$ Catal. Lett. 11269 